\title{
A CONSCIENTIZAÇÃO QUANTO À NECESSIDADE DE ATUAÇÃO COM SERIEDADE NA PROTEÇÃO COLETIVA PREVENTIVA: Um Mecanismo para a Transformação da Sociedade e do Estado Brasileiro
}

http://dx.doi.org/10.21527/2176-6622.2021.56.9401

Recebido em: 22/8/2019

Modificações solicitadas em: 28/4/2021

Aceito em: 14/5/2021

Rodrigo Antônio Ribeiro Storino

Autor correspondente. Universidade de Itaúna - UIT. Rodovia MG 431, Km 45, s/n. Itaúna/MG, Brasil. CEP 35680-142. http://lattes.cnpq.br/4380157760081426. https://orcid.org/0000-0002-9668-9257. storinoo@yahoo.com.br

Eloy Pereira Lemos Júnior

Universidade de Itaúna - UIT. Itaúna/MG, Brasil.

\section{RESUMO}

A temática da pesquisa é a análise do perfil do direito coletivo brasileiro, que se apresenta como fator contributivo para prevenção de danos sociais. O tema possui relevância para efetiva modificação da postura da sociedade e Estado brasileiro diante dos perigos e riscos detectados cotidianamente, evitando danos coletivos graves e irreversíveis. Questionou-se neste artigo se a priorização da proteção coletiva preventiva é mecanismo eficaz para inibir e fazer cessar a reiteração de práticas ilícitas geradoras de danos sociais. $O$ marco teórico utilizado foi o enfoque neoconstitucionalista próprio do modelo constitucional brasileiro inaugurado em 1988, o qual instituiu a nova summa divisio entre direitos individuais e coletivos. Concluiu-se pela necessidade de modificação de filosofia e postura da sociedade e Estado brasileiro, para a aplicação com seriedade da sistematização jurídica existente, como mecanismo de evitar danos coletivos, pois não se amolda ao modelo constitucional brasileiro atuação individualista e patrimonialista, bem como postura passiva diante dos perigos e riscos que se apresentam. A metodologia utilizada foi a revisão bibliográfica, com delimitação do problema por meio do método dedutivo, realizando-se ainda análise explicativa histórica da evolução das teorias do Estado e análise interpretativa crítica dos obstáculos a efetividade do direito coletivo brasileiro.

Palavras-chave: Constitucionalismo brasileiro; nova summa divisio; proteção coletiva preventiva; princípio da precaução; danos sociais.

THE CONSCIENTIZATION OF THE NEED TO ACT WITH SERIOUSNESS IN PREVENTIVE COLLECTIVE PROTECTION: A MECHANISM FOR TRANSFORMING SOCIETY AND THE BRAZILIAN STATE

\section{ABSTRACT}

The research theme is the analysis of the profile of Brazilian collective law, which presents itself as a contributory factor for the prevention of social damages. The theme has relevance for effective modification of the posture of the Brazilian society and State in face of the dangers and risks detected daily, avoiding serious and irreversible collective damages. Asked in this article if the prioritization of preventive collective protection is an effective mechanism to inhibit and stop the repetition of illegal practices that generate social damages. The theoretical framework used was the neoconstitutionalist approach of the Brazilian constitutional model inaugurated in 1988, which instituted the new summa division between individual and collective rights. It was concluded that there is a need to modify the philosophy and posture of the Brazilian society and State, in order to apply seriously the existing legal systematization, as a mechanism to avoid collective damages, because it does not conform to the Brazilian constitutional model, individualist and patrimonialist performance, as well as posture passive in the face of dangers and risks. The methodology used was the bibliographical revision, with delimitation of the problem through the deductive method, and a historical explanatory analysis of the evolution of State theories and critical interpretative analysis of obstacles to the effectiveness of Brazilian collective law.

Keywords: Brazilian constitutionalism; new summa divisio; preventive collective protection; principle of precaution; social damages. 
A CONSCIENTIZAÇÃO QUANTO À NECESSIDADE DE ATUAÇÃO COM SERIEDADE NA PROTEÇÃO COLETIVA PREVENTIVA: UM MECANISMO PARA A TRANSFORMAÇÃO DA SOCIEDADE E DO ESTADO BRASILEIRO

Rodrigo Antônio Ribeiro Storino - Eloy Pereira Lemos Júnior

\section{INTRODUÇÃO}

O objetivo geral desta pesquisa é comprovar que a priorização da proteção coletiva preventiva é mecanismo para transformação com justiça da sociedade e do Estado brasileiro, no intuito de evitar condutas ilícitas geradoras de danos sociais gravíssimos e irreversíveis.

O tema possui densa relevância prática, pois se consubstancia na indução à modificação da postura passiva da sociedade e Estado brasileiro diante dos perigos e riscos identificados em condutas ilícitas, mesmo que ainda não causadoras de danos.

Justifica-se também a pesquisa sob o ponto de vista teórico, para ressaltar que a priorização de proteção coletiva preventiva configura forma de efetivação dos direitos fundamentais, atendendo aos objetivos constitucionais de construção de uma sociedade brasileira justa, solidária e que trate seus cidadãos com dignidade.

Há ainda relevância científica para buscar reflexão crítica dos operadores do Direito quanto ao perfil do direito coletivo já traçado pelo legislador constitucional, mostrando-se necessária mudança no pensamento jurídico dominante, para o alcance da eficácia social desejada aos direitos coletivos.

Na segunda parte do trabalho tem-se a análise do modelo de constitucionalismo brasileiro inaugurado em 1988, do Estado Democrático de Direito e dos direitos coletivos, além das discussões sobre a teoria das normas constitucionais e do paradigma neoconstitucionalista.

Já na terceira parte passa-se a compreender as reflexões críticas sobre como a postura da sociedade e do Estado brasileiro revelam-se obstáculo à efetividade dos direitos fundamentais coletivos, além de tratar dos princípios da prevenção e precaução aos danos sociais e a responsabilidade civil e os danos punitivos que se quer aplicadas àqueles.

Nesta temática questiona-se neste artigo científico: A priorização da proteção coletiva preventiva é mecanismo eficaz para inibir e fazer cessar a reiteração de práticas ilícitas geradoras de danos sociais graves e irreversíveis?

Pressupõe essa pesquisa como hipótese científica que, em virtude do modelo de constitucionalismo brasileiro adotado, o qual dividiu o ordenamento jurídico pátrio em direitos individuais e coletivos, estipulando como ponto marcante de seu perfil a proteção coletiva preventiva. Nesse sentido, cabe à sociedade brasileira e seus legitimados atuação precaucional na identificação e combate a ilícitos como mecanismo de prevenção de danos sociais.

A partir de revisão bibliográfica foi possível debater criticamente a temática posta sob o enfoque neoconstitucionalista próprio do modelo constitucional brasileiro inaugurado em 1988, o qual instituiu a nova summa divisio entre direitos individuais e coletivos, o que serviu de marco teórico para este estudo.

A delimitação do problema ocorreu pelo método dedutivo, partindo-se de concepções macroanalíticas do direito coletivo consagrado em sede constitucional, para extração de afirmações específicas quanto à necessidade de proteção coletiva preventiva como modelo próprio para o combate a condutas ilícitas e danos sociais no Brasil.

\section{O MODELO DE CONSTITUCIONALISMO BRASILEIRO, ESTADO DEMOCRÁTICO E DIREITOS FUNDAMENTAIS COLETIVOS}

O modelo de constitucionalismo brasileiro materializa-se com a Constituição da República Federativa do Brasil de 1988, a qual, já em seu artigo 1o, estabelece a formatação de um Estado Democrático de Direito.

Com Lenio Luiz Streck, "o Estado Democrático de Direito é um novo paradigma porque foi engendrada uma nova legitimidade no campo do direito constitucional e da ciência política, no interior da qual o direito assume tarefa de transformação" (2003, p. 690).

Diante da nova lógica posta, o Direito assume o protagonismo na tentativa de modificar, para melhor, a vida de cada indivíduo e da sociedade como um todo. Ganham relevância os direitos fundamentais como valores imperativos básicos para a convivência em sociedade. Em verdade, a sustentação e funcionamento de um grupo social depende do estabelecimento harmonioso dos institutos fundamentais norteadores das decisões dos cidadãos. 
A CONSCIENTIZAÇÃO QUANTO À NECESSIDADE DE ATUAÇÃO COM SERIEDADE NA PROTEÇÃO COLETIVA PREVENTIVA: UM MECANISMO PARA A TRANSFORMAÇÃO DA SOCIEDADE E DO ESTADO BRASILEIRO

Rodrigo Antônio Ribeiro Storino - Eloy Pereira Lemos Júnior

Pode-se afirmar que os direitos fundamentais originam-se de construções históricas, iniciadas a partir das revoluções burguesas do final do século 18, baseadas nas necessidades sociais apresentadas em cada época. Dessa forma, são valores em constantes mutações, os quais depois de conquistados não podem retroagir, mas permitem que outros a eles se agreguem.

A partir desta linha de raciocínio, com Ingo Wolfgang Sarlet construiu-se a ideia de dimensões de direitos fundamentais. Em que pese a imprecisão quanto ao número de dimensões atualmente existentes, ressalta o autor que o vocábulo 'dimensão' expressa a ideologia de que os direitos fundamentais formam um todo unitário de valores essenciais à sociedade, afastando a ideia de compartimentação advinda da expressão gerações de direitos fundamentais (SARLET, 2005, p. 53).

Essencial é entender a natureza jurídica dos direitos fundamentais como princípios em contraposição às políticas (DWORKIN, 2002, p. 36).

Os argumentos de política são objetivos a serem alcançados pela sociedade. Estes objetivos futuros servem como uma espécie de trilha para as decisões políticas tomadas em um Estado de Direito. Já os direitos fundamentais, como princípios, são garantidores de que os valores selecionados como essenciais pela sociedade serão sempre respeitados ao longo do percurso da trilha traçada previamente pelo legislador constituinte.

Por isso, as decisões políticas devem ser tomadas em consonância com os direitos fundamentais. Caso isto não ocorra, deve o poder Judiciário realizar o controle de tais atos atentatórios. Assim, verifica-se a fulcral função de acesso à Justiça destinada ao poder Judiciário no Estado Democrático de Direito, pelo que se pode afirmar a opção constitucional de prevalência do Direito sobre a política.

E mais, o legislador constituinte brasileiro de 1988 positivou os direitos fundamentais individuais e coletivos para enfatizar a preocupação com a proteção integral dos direitos humanos na ordem interna.

No que diz respeito à natureza jurídica de direito fundamental dos direitos coletivos ensina Gregório Assagra de Almeida que:

A Constituição brasileira atual inovou na proteção dos direitos e interesses massificados, conferindo-lhes dignidade constitucional própria para uma nação democrática que pretenda transformar a realidade social. Não há como transformar a realidade social sem a eliminação das desigualdades e injustiças sociais, sem a proteção integral e efetiva dos direitos coletivos, amplamente considerados (ALMEIDA, 2008, p. 359).

Não basta, contudo, a consagração dos direitos fundamentais se não forem previstas garantias à efetivação e respeito destes direitos. Neste sentido, a imposição de dano moral coletivo aos atos ofensivos aos direitos fundamentais de uma coletividade representa verdadeira garantia a estes direitos, bem como mecanismo de preservação do Estado Democrático de Direito brasileiro.

Verifica-se que o constituinte de 1988 colmatou o interesse social prevendo, de um lado, o dano moral coletivo como garantia fundamental e, de outro, o direito coletivo como verdadeiro direito fundamental constitucional formatado por um sistema processual coletivo.

Nesse sentido, o processo coletivo possui matriz constitucional, ${ }^{1}$ sendo sua sistemática complementada em diálogo das fontes pelas normas infraconstitucionais, em especial por seu núcleo formado pela Lei de Ação Civil Pública² e Código de Defesa do Consumidor. ${ }^{3}$

Para Gregório Assagra de Almeida, "o objeto formal do direito coletivo é o conjunto de princípios, garantias e regras que disciplinam a proteção e a efetivação de todos os interesses coletivos", compondo o sistema processual coletivo (ALMEIDA, 2008, p. 14).

\footnotetext{
$1 \mathrm{CF} / 88$.

Art. 129. São funções institucionais do Ministério Público:

[...]

III - promover o inquérito civil e a ação civil pública, para a proteção do patrimônio público e social, do meio ambiente e de outros interesses difusos e coletivos.

2 Lei $7.347 / 1985$.

3 Lei 8.078/1990.
} 
A CONSCIENTIZAÇÃO QUANTO À NECESSIDADE DE ATUAÇÃO COM SERIEDADE NA PROTEÇÃO COLETIVA PREVENTIVA: UM MECANISMO PARA A TRANSFORMAÇÃO DA SOCIEDADE E DO ESTADO BRASILEIRO

Rodrigo Antônio Ribeiro Storino - Eloy Pereira Lemos Júnior

De outro lado, sob o aspecto material, o direito coletivo configura-se nos direitos difusos, coletivos e individuais homogêneos, os quais, se violados, ofendem os direitos fundamentais da sociedade, ensejando a estipulação de danos morais coletivos.

Com o estabelecimento de natureza fundamental aos direitos coletivos, sem qualquer tipo de hierarquização em relação aos direitos individuais, inaugurou a Constituição da República Federativa do Brasil de 1988, em seu capítulo I do título II, uma nova summa divisio no Direito brasileiro.

Esta nova summa divisio é ponto marcante do modelo de constitucionalismo brasileiro inaugurado em 1988, representando muito mais do que mera mudança de nomenclatura, pois visa a ressaltar a mudança de filosofia inaugurada com a Constituição.

Isso porque, ao longo do Estado Social anterior a 1988, havia separação entre a sociedade brasileira e o Estado. As relações sociais eram regidas pelo Direito Privado, enquanto as situações que tivessem em um ou ambos os polos da relação jurídica o Estado eram regidas pelo Direito Público.

A antiga divisão do Direito brasileiro entre público e privado desamparava a sociedade de direitos fundamentais. O Direito Privado era estanque, resolvendo suas demandas em si mesmo. Desta forma, a norma paradigma para as relações jurídicas da sociedade era o Código Civil de 1916, o qual tinha como características ser patrimonialista, individualista e formado por regras.

Noutro giro, o Estado Social, regido pelo Direito Público, tendo como norma paradigma a Constituição, vista como mera carta política, tinha nele mesmo o seu fim, o que explica sua ineficácia na efetivação de direitos fundamentais que pertenciam à sociedade, a qual orbitava o outro plano do Direito brasileiro.

Esse isolamento e desamparo social acaba com a nova summa divisio de 1988, pois o Estado é inserido na sociedade, passando a servi-la, sendo responsável por sua modificação para melhor, tendo em vista que a chave de partida do Estado Democrático é que todo poder emana do povo.

Ausente a dicotomia Estado/Sociedade, perde sentido a divisão entre Direito Público e Direito Privado. Pelo fato de a sociedade ser soberana no Estado Democrático, tem ela direitos fundamentais, individuais e coletivos estabelecidos pela Constituição, a qual, com viés jurídico, irradia seus valores por todo o Direito.

Nesse enfoque, o Estado deixa de ter nele mesmo o seu fim, passando a projetar sua atuação para a garantia e efetivação dos direitos fundamentais de cada um dos seus indivíduos (direito fundamental individual), bem como do conjunto de indivíduos que formam a sociedade (direito fundamental coletivo).

Com isso, os direitos coletivos assumem a roupagem de direitos fundamentais e, sob a ótica objetiva, passam a necessitar de regras e princípios próprios que permitam sua efetivação material, modificando de fato, para melhor, o cotidiano de seus titulares.

\subsection{As discussões sobre a teoria das normas constitucionais: princípios $x$ regras e o paradigma neoconstitucionalista}

A diferenciação entre regras e princípios é idealizada por Robert Alexy, citado por Carlos Bernal Pulido, na qual as regras são mandamentos de definição, que possibilitam o cumprimento ou descumprimento de forma integral diante do caso concreto. De outro lado, os princípios são mandamentos de otimização, os quais devem ser realizados na maior medida possível na situação posta, podendo assim haver cumprimento destes em graus diversos no fato analisado (PULIDO, 2003, p. 572).

Nas lições de Virgílio Afonso da Silva, enquanto o conflito entre regras resolve-se no plano da validade da norma aplicada, o conflito entre princípios resolve-se pela ponderação, tendo como parâmetro a proporcionalidade, sem declaração de invalidade das normas em disputa. Ressalta o mesmo autor que princípios e regras garantidores de direitos fundamentais possuem a mesma densidade jurídica para resolução de casos concretos, pois aplicam-se diretamente a estes em decorrência de opção legislativa prevista no artigo 5ㅇ, §1으, da Constituição Federal de 1988 (SILVA, 2005, p. 30-35).

Nessa linha de raciocínio em que se aplicam diretamente as normas constitucionais na solução de casos concretos, ganha relevância a função exercida pelo poder Judiciário no modelo de constitucionalismo brasileiro, haja vista a possibilidade de prolação da decisão mais apropriada ao caso concreto perpassando pelos 
A CONSCIENTIZAÇÃO QUANTO À NECESSIDADE DE ATUAÇÃO COM SERIEDADE NA PROTEÇÃO COLETIVA PREVENTIVA: UM MECANISMO PARA A TRANSFORMAÇÃO DA SOCIEDADE E DO ESTADO BRASILEIRO

Rodrigo Antônio Ribeiro Storino - Eloy Pereira Lemos Júnior

princípios e regras presentes no sistema jurídico. Essa nova lógica constitucional é denominada de neoconstitucionalismo, o qual é contextualizado da seguinte forma por Luís Roberto Barroso:

O novo direito constitucional ou neoconstitucionalismo desenvolveu-se na Europa, ao longo da segunda metade do século XX, e, no Brasil, após a Constituição Federal de 1988. O ambiente filosófico em que floresceu foi o do pós-positivismo, tendo como principais mudanças de paradigma, no plano teórico, o reconhecimento da força normativa à Constituição, a expansão da jurisdição constitucional e a elaboração das diferentes categorias de nova interpretação constitucional (BARROSO, 2007, p. 173).

O neoconstitucionalismo possibilita que o poder Judiciário seja elemento de transformação social e acesso à Justiça, construindo de forma participada e fundamentada a decisão mais justa à demanda posta. Assim, opera-se com o neoconstitucionalismo a virada kantiana, haja vista a reaproximação do Direito e da moral, sob o paradigma pós-positivista, quando a lei deixa de ser a única fonte para as decisões.

Temos assim que o neoconstitucionalismo fornece aos operadores do Direito uma nova lente interpretativa e de aplicação da Constituição. Nas lições de Gregório Assagra de Almeida, "a finalidade é superar barreiras impostas ao Estado Constitucional Democrático de Direito pelo positivismo meramente legalista, gerador de bloqueios ilegítimos ao projeto constitucional de transformação da realidade social" (ALMEIDA, 2008 , p. 135). Esta postura emancipadora permite a construção de uma sociedade aberta dos intérpretes da Constituição, conforme a teoria desenvolvida por Peter Häberle, a qual se amolda com a sistemática do Estado Democrático Direito e com os direitos coletivos fundamentais trazidos pelo modelo de constitucionalismo brasileiro (HÄBERLE, 1997, p. 139).

Por essa lógica, considerando que os princípios são orientações gerais do sistema jurídico, os quais se aplicam diretamente para solução de demandas; bem como pressupondo que os direitos coletivos possuem finalidades específicas e distintas dos direitos individuais, necessária a construção de arcabouço principiológico próprio para estes direitos, justamente para que possam ter a efetividade esperada no paradigma de um Estado Democrático de Direito como o brasileiro.

Não por outro motivo, o princípio estruturante para a aplicação do direito coletivo brasileiro é o Princí-

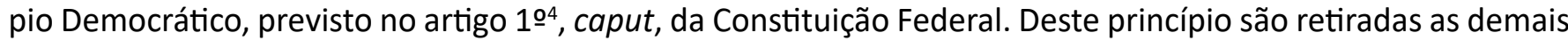
interpretações de direito coletivo. Nas palavras de José Joaquim Gomes Canotilho deve ser compreendido o princípio democrático da seguinte forma:

O princípio democrático não se compadece com uma compreensão estática de democracia. Antes de mais nada, é um processo de continuidade 'transpessoal', irredutível a qualquer vinculação do processo político a determinadas pessoas. Por outro lado, a democracia é um processo dinâmico inerente a uma sociedade aberta e ativa, oferecendo aos cidadãos a possibilidade de desenvolvimento integral [...] (CANOTILHO, 1998, p. 279).

Princípio que também merece destaque é o da solidariedade coletiva, previsto no artigo 3ํㅗㄴ, I, da Constituição Federal de 1988. Trata-se de objetivo traçado pelo constituinte no intuito de desenvolver cidadãos conscientes da função social que deve ser desempenhada por todos para alcance de uma sociedade livre e justa.

Não se pretende, a partir deste, retirar a autonomia impulsionadora do alcance de metas individuais, mas sim agregar a essa vertente a necessidade de observar os interesses de todos, devendo o exercício dos direitos individuais estar de acordo com o direito da coletividade. Desta orientação geral dos direitos coletivos retira-se a necessidade de tratamento com igual respeito e consideração às diferenças, tratando-se de efetiva-

\footnotetext{
${ }^{4} \mathrm{CF} / 88$.

Art. 1으 A República Federativa do Brasil, formada pela união indissolúvel dos Estados e Municípios e do Distrito Federal, constitui-se em Estado Democrático de Direito e tem como fundamentos:

$[\ldots]$

$\mathrm{CF} / 88$.

Art. 3을 Constituem objetivos fundamentais da República Federativa do Brasil:

I - construir uma sociedade livre, justa e solidária;

$[\ldots]$
} 
A CONSCIENTIZAÇÃO QUANTO À NECESSIDADE DE ATUAÇÃO COM SERIEDADE NA PROTEÇÃO COLETIVA PREVENTIVA: UM MECANISMO PARA A TRANSFORMAÇÃO DA SOCIEDADE E DO ESTADO BRASILEIRO

Rodrigo Antônio Ribeiro Storino - Eloy Pereira Lemos Júnior

ção dos direitos majoritários e minoritários, ou seja, de todo o povo, o que se coaduna com o ideal republicano e democrático brasileiro.

Outros princípios que ainda orientam o direito coletivo, inaugurado em 1988, são os Princípios da Não Taxatividade e da Vedação ao Retrocesso, interpretados a partir do artigo 5으, §2ํㅡ, da Constituição Federal, que evidenciam a amplitude dada a estes direitos fundamentais pelo legislador.

Dessa construção jurídica extrai-se o princípio tema desta pesquisa, qual seja, o Princípio da Priorização da Proteção Coletiva Preventiva.

A consagração dos direitos coletivos como direitos fundamentais comprova a preocupação que o Direito deve ter com o todo, não bastando a proteção do indivíduo, mas sim a proteção da sociedade. Além da vertente passiva de proteção, deve o Direito ser utilizado como mecanismo ativo de modificação da vida dos indivíduos e da sociedade como grupo unitário.

Nesta vertente, alguns danos perpassam a esfera individual e atingem a coletividade. Os danos coletivos ou sociais podem atingir a sociedade de modo integral, sendo o interesse difuso violado; ou de modo parcial, quando o interesse de um grupo é atingido.

Em geral, os danos sociais por serem coletivos são de extrema gravidade e irreparáveis in natura. Com isso, diante da impossibilidade de retorno ao estado anterior, o prejuízo à sociedade é patente e irreversível, não sendo capaz de ser afastado por meio de eventual compensação financeira realizada pelo causador do dano.

Desta forma, há necessidade de atuar de forma séria na prevenção de danos coletivos, pois a sua mera ocorrência prejudica de modo irreparável o direito de todos ou de um grupo. Com isso, extrai-se o Princípio da Priorização da Proteção Coletiva Preventiva do artigo 5으, §2으, da Constituição Federal, posto que este atende ao modelo de constitucionalismo brasileiro inaugurado em 1988.

Neste tópico demonstrou-se que o Direito brasileiro já possui sistematização jurídica para proteção de sua sociedade diante de danos coletivos. O próximo item procura demonstrar que a priorização da proteção coletiva preventiva é mecanismo eficaz para inibir e fazer cessar a reiteração de práticas ilícitas geradoras de danos sociais graves e irreversíveis, devendo haver modificação de postura da sociedade e do Estado brasileiro para concessão de efetividade ao modelo constitucional previsto.

\section{A POSTURA DA SOCIEDADE CIVIL E DO ESTADO BRASILEIRO E O REFLEXO NA EFETIVIDADE DOS DIREITOS FUNDAMENTAIS COLETIVOS}

A sociedade brasileira, em geral, mantém-se passiva diante de condutas violadoras de direitos fundamentais ainda não geradoras de danos sociais, manifestando-se apenas após ocorrência do dano. Exemplifica-se o afirmado com o notório fato do incêndio na Boate Kiss, ocorrido em 27 de janeiro de 2013, em Santa Maria, Rio Grande do Sul, gerador de 242 vítimas fatais e 680 vítimas não fatais. O fato ocorreu em casa noturna desprovida de laudo de prevenção e combate a incêndios expedido pelo Corpo de Bombeiros Militar, na qual se realizava uma apresentação musical com fogos de artifício.

Saindo deste caso concreto e passando a uma análise genérica de situações semelhantes, verifica-se que o senso comum evidencia o perigo de utilização de material inflamável em imóvel fechado; bem como o risco de um local, sem as devidas autorizações, promover evento para receber grande público. Estas condutas, entretanto, são praticadas diante da cegueira deliberada da sociedade, haja vista a ausência de danos em hipóteses semelhantes anteriores. Após o resultado danoso, por óbvio, a sensação é de revolta e indignação, porém eventuais atuações preventivas tendentes a inibir a ocorrência do evento ou proibir a utilização do material inflamável são, na maioria das vezes, encaradas com desdenho, como meros formalismos desneces-

\footnotetext{
6 Art. 5‥ Todos são iguais perante a lei, sem distinção de qualquer natureza, garantindo-se aos brasileiros e aos estrangeiros residentes no país a inviolabilidade do direito à vida, à liberdade, à igualdade, à segurança e à propriedade, nos termos seguintes:

$[\ldots]$

§2ㅇ Os direitos e garantias expressos nesta Constituição não excluem outros decorrentes do regime e dos princípios por ela adotados, ou dos tratados internacionais em que a República Federativa do Brasil seja parte.
} 
A CONSCIENTIZAÇÃO QUANTO À NECESSIDADE DE ATUAÇÃO COM SERIEDADE NA PROTEÇÃO COLETIVA PREVENTIVA: UM MECANISMO PARA A TRANSFORMAÇÃO DA SOCIEDADE E DO ESTADO BRASILEIRO

Rodrigo Antônio Ribeiro Storino - Eloy Pereira Lemos Júnior

sários. Enfim, o risco e o perigo não são tidos como fatores de mobilização social, o que só ocorre a partir do dano que, como visto, em regra é irreparável na seara coletiva.

É preciso difundir educação que desperte na sociedade uma postura de intransigência diante do risco e do perigo. A cidadania brasileira necessita ser solidarista. Não há mais espaço na sociedade de risco contemporânea para o jeitinho. Não há mais espaço para tratamento diferenciado entre o conhecido como meu direito individual e o direito coletivo, como se esse último direito fosse dos outros.

A filosofia solidarista coletiva deve estar incutida nos brasileiros do século 21 , os quais devem sair às ruas antes das grandes chuvas de verão, para cobrar investimentos em infraestrutura urbana básica; que devem sair às ruas para cobrar estruturação e fiscalização dos órgãos ambientais, antes do rompimento de barragens; que devem sair às ruas diante do risco e do perigo, não podendo aguardar a ocorrência do dano, sob pena de impossibilidade de retorno ao estado anterior.

A pressão social diante dos riscos e perigos busca operar modificação da postura estatal com a promoção de proteção coletiva preventiva, sob pena de manutenção do atual quadro fático, no qual continuam ocorrendo danos graves e irreparáveis por riscos e perigos já detectados, sem que nenhuma atitude concreta seja tomada, considerando os novos eventos como tragédias isoladas e inesperadas.

Mais uma vez retorna-se ao exemplo do incêndio na Boate Kiss para observar que, após este evento, nada mudou quanto à política pública relacionada à autorização do Corpo de Bombeiros Militar para funcionamento de estabelecimentos sem laudo de prevenção e combate a incêndios, o qual continua sendo tratado como mero ornamento, e não como eficaz mecanismo de prevenção.

Para comprovar o anteriormente afirmado basta recordar de outros dois notórios incêndios ocorridos depois do fato na Boate Kiss, em locais que funcionavam sem a referida autorização do Corpo de Bombeiros Militar. O primeiro deles deu-se no Museu Nacional, em 2 de setembro de 2018, no Rio de Janeiro, quando foram destruídos diversos objetos responsáveis por materializar a História do Brasil; e o segundo ocorreu no Ninho do Urubu, concentração do Clube de Regatas do Flamengo, também no Rio de Janeiro, em 8 de fevereiro de 2019, que vitimou de modo fatal 10 jovens que se encontravam no local.

Estas três tragédias não teriam ocorrido caso o Princípio da Priorização da Proteção Coletiva Preventiva fosse respeitado, com a simples e óbvia atitude de se proibir o funcionamento de locais que não possuam autorização do Corpo de Bombeiros Militar quanto à prevenção e combate a incêndios.

Há necessidade da sociedade e do Estado brasileiros levarem o risco e o perigo a sério, utilizando-se dos mecanismos jurídicos previstos em nosso sistema para evitar danos coletivos graves e irreparáveis.

O Direito, como ciência que regula a vida em sociedade, tem procurado desenvolver institutos que efetivem a proteção coletiva preventiva. Já se apontou nesta pesquisa a nova summa divisio constitucionalizada em 1988, a qual coloca o direito coletivo como direito fundamental, criando metodologia própria para a sua aplicação. Entre os princípios reguladores do direito coletivo encontra-se o princípio da priorização da proteção coletiva preventiva, que se aplica diretamente aos fatos sociais.

No que respeita especificamente à prevenção de danos sociais, o Direito desenvolveu ainda os princípios da prevenção e precaução, na busca de evitar a ocorrência dos referidos danos.

\subsection{Os princípios da prevenção e precaução aos danos coletivos, responsabilidade civil e danos punitivos}

O princípio da prevenção está diretamente relacionado ao perigo, ou seja, quando já conhecida uma situação perigosa o direito determina atitudes preventivas do Estado e da sociedade para evitar o dano iminente. Exemplifica-se a aplicação do princípio da prevenção nas multas de trânsito impostas a quem insiste em imprimir velocidade excessiva nas vias ou praticar ultrapassagens em locais proibidos.

Já o princípio da precaução representa etapa protetiva anterior ao perigo, estando diretamente relacionado ao risco. Nestes casos, apesar da situação de perigo ainda ser potencial, e não concreta, o Direito determina atitudes precaucionais do Estado e da sociedade para evitar o potencial dano coletivo futuro, o que se justifica pela seriedade e irreversibilidade deste. Exemplifica-se a aplicação do princípio da precaução com $\mathrm{o}$ isolamento e quarentena de grupo de pessoas que provavelmente adquiriram doença grave e contagiosa. 
A CONSCIENTIZAÇÃO QUANTO À NECESSIDADE DE ATUAÇÃO COM SERIEDADE NA PROTEÇÃO COLETIVA PREVENTIVA: UM MECANISMO PARA A TRANSFORMAÇÃO DA SOCIEDADE E DO ESTADO BRASILEIRO

Rodrigo Antônio Ribeiro Storino - Eloy Pereira Lemos Júnior

Existem críticas à aplicação dos princípios da prevenção e precaução no sentido de que estes dificultam o progresso econômico, científico e social, pois se proíbe determinadas condutas independentemente da existência de um dano, com base em probabilidades e estatísticas. Defende-se nesta pesquisa que tais críticas não merecem prosperar, pois partem do pressuposto individualista e não solidarista, o qual impera quando o assunto envolver direitos coletivos; adota-se, também, o posicionamento da celebrada autora e autoridade na seara da defesa e proteção dos direitos humanos e fundamentais, professora Flávia Piovesan, quando aborda o tema dos referidos princípios.

O progresso, em qualquer de suas vertentes, somente deve ocorrer quando em segurança a sociedade, principalmente a atual sociedade de risco, a qual vive sob constante medo. Não é possível neste paradigma transigir com o risco e permitir a violação de direitos fundamentais.

Análise histórica auxilia nesta conclusão quando se observa que, na década de 80 do século 20, ainda sob perspectiva individualista de uma sociedade industrial, permitiu-se na França a continuidade nas transfusões de sangue, mesmo diante da probabilidade de contaminação das pessoas pelo vírus HIV, haja vista que àquela altura não havia comprovação de que se tratava de vírus fatal transmitido nos referidos procedimentos médicos, ou seja, ainda não havia comprovação do dano, somente do risco. Milhares de vidas foram perdidas diante da falta de atuação preventiva coletiva estatal, não sendo permitido incorrer em erros semelhantes atualmente.

O fundamento ético para atuação preventiva coletiva está no princípio da responsabilidade consagrado na doutrina de Hans Jonas, que defende que diante das incertezas que marcam a sociedade contemporânea "é necessário dar mais ouvidos à profecia da desgraça do que à profecia da salvação" (JONAS, 2006, p. 77), em especial devido à impossibilidade, como regra, de reparação dos danos sociais.

O modelo constitucional brasileiro apresenta fundamentos jurídicos para aplicação dos princípios da prevenção e precaução nos artigos 3ㅇ, I, 5ㅇ, XXXV, e 6으, caput, todos da Constituição Federal de 1988, haja vista traçar como objetivo a construção de uma sociedade solidária, que deve agir diante de ameaças a direitos, para garantir a segurança social. O Brasil ainda acolheu estes princípios na seara internacional ao aderir à Carta do Rio de Janeiro (ONU, 1992), na ECO 92, a qual prevê expressamente em seu Princípio $15^{7}$ a necessidade de respeito ao princípio da precaução. Ainda na esfera legal encontra-se fundamento coletivo para adoção destes princípios quando, no artigo 60 $1^{8}$, do Código de Defesa do Consumidor, consta proibição de fornecimento de produtos e serviços perigosos ou nocivos, garantindo-se o direito básico de segurança ao consumidor.

Diante do medo que permeia a sociedade atual, o Direito opera mutação para ampliar sua proteção. Por isso, com a adoção dos princípios da prevenção e precaução, não é necessário aguardar a ocorrência de dano para incorrer em responsabilidade. Muito pelo contrário, detectado o perigo ou o risco, já há possibilidade de responsabilização dos seus causadores. Neste sentido, a lição de Tereza Ancona Lopez:

Antes a noção de risco satisfazia; agora, há uma noção a ser reconhecida, a da incerteza. As obrigações morais tomam a mesma forma da ética e a responsabilidade aparece como reflexo da noção de precaução. Assim, é o paradigma da segurança que transforma os princípios da responsabilidade e da solidariedade em princípio da precaução. Esse paradigma tem, no princípio da precaução, sua melhor aposta (LOPEZ, 2013, p. 8).

A ética trazida ao Direito brasileiro pelo neoconstitucionalismo afetou diretamente o instituto da responsabilidade civil. Se antes, diante de demandas individuais e patrimonialistas, a responsabilidade civil meramente compensatória do dano causado respondia aos anseios sociais, atualmente este instituto precisa ir além para cumprir sua função social.

ONU. Princípio 15 - De modo a proteger o meio ambiente, o princípio da precaução deve ser amplamente observado pelos Estados, de acordo com as suas capacidades. Quando houver ameaça de danos sérios ou irreversíveis, a ausência de absoluta certeza científica não deve ser utilizada como razão para postergar medidas eficazes e economicamente viáveis para prevenir a degradação ambiental.

8 Lei n. 8078/90.

Art. 60 São direitos básicos do consumidor:

I - a proteção da vida, saúde e segurança contra os riscos provocados por práticas no fornecimento de produtos e serviços considerados perigosos ou nocivos;

$[\ldots]$ 
A CONSCIENTIZAÇÃO QUANTO À NECESSIDADE DE ATUAÇÃO COM SERIEDADE NA PROTEÇÃO COLETIVA PREVENTIVA: UM MECANISMO PARA A TRANSFORMAÇÃO DA SOCIEDADE E DO ESTADO BRASILEIRO

Rodrigo Antônio Ribeiro Storino - Eloy Pereira Lemos Júnior

A responsabilidade civil contemporânea se multifuncionalizou para poder tutelar o perigo e o risco. Por isso, além de compensatório, o instituto é também preventivo, podendo ser até mesmo punitivo, em situações extremas em que se constate dolo ou culpa grave na causação de danos sociais.

Foram criados standards para atuação estatal na seara da responsabilidade civil. Assim, quando houver dano isolado e meramente individual, a função compensatória clássica de retorno ao estado anterior é suficiente. Caso constatado perigo, risco ou mesmo dano com potencial coletivo, além da compensação financeira do eventual prejuízo, necessária a utilização da função preventiva com a imposição de outras obrigações de natureza diversa, que façam cessar o perigo e o risco identificados, bem como evitem a ocorrência de danos futuros semelhantes. O último standard reserva-se aos atos de maior gravidade, causadores de danos sociais advindos de condutas dolosas ou por culpa grave, aos quais, além da aplicação de medidas compensatórias e preventivas, aplica-se a função punitiva com o pagamento de quantia superior ao dano causado.

Exemplifica-se a necessidade de dano punitivo no caso em que uma fabricante de veículos projeta um de seus modelos sabendo que este emite gases poluidores tóxicos capazes de prejudicar a saúde humana e o meio ambiente. Ainda assim, diante do perigo, ao invés de desistir do projeto, a fabricante faz a opção pela criação de sistema de emissão de gases capaz de fraudar os testes a que o projeto será submetido. Com sua conduta dolosa e antiética, a fabricante vende seus veículos por anos, até que a fraude é descoberta. Não basta ressarcir quem comprou os veículos pelos valores pagos, pois a conduta vulnerou toda a sociedade. Há necessidade de punição para determinar o pagamento de quantia referente a todos os lucros daquela empresa pelos anos em que o veículo foi vendido, o qual deve ser destinado a fundo social referente aos direitos fundamentais à saúde e ao meio ambiente.

Esta aplicação multifuncional da responsabilidade civil com as funções preventivas e punitivas é aquela capaz de fornecer a resposta proporcional ao caso concreto, o que não ocorreria se aplicada somente à função compensatória pelos danos causados, pelo que outras condutas semelhantes seriam incentivadas. Explorando tal linha de raciocínio aduzem Lemos Junior e Silva que a sociedade moderna "não pôde ser contida, controlada, como os líquidos e gases também não podem ser contidos quando são pressionados a certo destino; não são sólidos, não são estáveis, e é praticamente impossível controlar ou impedir sua mudança" (2016, p. 912). Neste quadro social fluido, com maior número de questionamentos do que respostas, o papel do Direito é de enfrentar as novas necessidades para desempenhar de forma adequada sua função social.

A legislação brasileira, contudo, não trata diretamente sobre a multifuncionalização da responsabilidade civil, pelo que há intensa controvérsia em sede doutrinária, em especial sobre a constitucionalidade da função punitiva independentemente de previsão expressa neste sentido.

O autor Nelson Rosenvald ensina que, em que pese a necessidade de multifuncionalização da responsabilidade civil, fato é que a função punitiva, por impor pena, ainda que civil, deve respeitar o princípio da legalidade estrita. Dessa forma, diante da ausência legislativa neste sentido, o instituto não pode ser aplicado ao Direito brasileiro (ROSENVALD, 2014, p. 77).

Já Caroline Vaz ressalta que os danos punitivos visam a proteger direitos fundamentais individuais e coletivos, devendo assim ser interpretados de acordo com o princípio da máxima eficácia, pelo que a multifuncionalização da responsabilidade civil converge com os valores trazidos pela Constituição Federal de 1988, devendo ser aplicada no Direito brasileiro (VAZ, 2009, p. 88).

Encontram-se julgados no Brasil impondo dano punitivo. Insere-se, contudo, o valor da punição no quantitativo arbitrado como dano moral, ${ }^{9}$ o que não se coaduna com a sistemática do dano punitivo originária do Direito anglo-saxão, na qual a função punitiva é autônoma, desvinculada da classificação dano material e moral.

\footnotetext{
BRASIL. Superior Tribunal de Justiça. REsp215607/RJ. Relator: Ministro Sálvio de Figueiredo Teixeira. 4a turma. DJ 13 set. $1999 ;$ BRASIL. Superior Tribunal de Justiça. REsp295175/RJ. Relator: Ministro Sálvio de Figueiredo Teixeira. 4a turma. DJ 2 abr. 2001 - nestes julgados determinou-se o pagamento de indenização por dano moral em valor considerado razoável a evitar condutas semelhantes futuras, no caso, segurança de shopping center agrediu consumidor que frequentava o local, impondo-se quantum superior à média arbitrada pelo tribunal para evitar novas violações no mesmo sentido.
} 
A CONSCIENTIZAÇÃO QUANTO À NECESSIDADE DE ATUAÇÃO COM SERIEDADE NA PROTEÇÃO COLETIVA PREVENTIVA: UM MECANISMO PARA A TRANSFORMAÇÃO DA SOCIEDADE E DO ESTADO BRASILEIRO

Rodrigo Antônio Ribeiro Storino - Eloy Pereira Lemos Júnior

Esta pesquisa busca a concessão de efetividade ao direito fundamental coletivo. Nesse sentido, no que se refere aos danos sociais, parece possível a aplicação da responsabilidade civil multifuncional para sua prevenção.

Possível, pois analisando o modelo constitucional brasileiro verifica-se a autorização de instauração direta dos direitos fundamentais coletivos para solução de casos concretos. E mais, os direitos fundamentais coletivos possuem como norte os princípios da máxima amplitude, máxima eficácia e priorização de proteção coletiva preventiva. Em que pese ausente lei expressa tratando do punitive damage no Direito brasileiro, certo é que este instituto se amolda à sistemática proposta pelo constituinte para os direitos coletivos na prevenção de danos sociais.

No que respeita à seara coletiva, a punição é revertida em favor da sociedade, uma vez que por força do artigo $13^{10}$ da Lei 7.347/85 a indenização destina-se a fundo coletivo, afastando-se de plano a crítica de que o dano punitivo causaria enriquecimento sem causa por parte da vítima.

Comprovado que a priorização da proteção coletiva preventiva é mecanismo eficaz para inibir danos sociais, bem como comprovada a existência de todo um modelo jurídico brasileiro capaz de prevenir estes danos, combatendo com eficácia os perigos e riscos, não há explicação lógica para que os poderes de Estado continuem se comportando de forma passiva diante destas incertezas, não instituindo de fato o projeto constitucional de Estado Democrático de Direito.

Exemplifica-se o afirmado a partir do notório fato do rompimento da barragem de Mariana, ocorrido em 5 de novembro de 2015, no subdistrito de Bento Rodrigues, pertencente ao município mineiro de Mariana, quando a barragem de rejeitos do empreendimento minerário da sociedade empresarial Samarco, da qual a empresa Vale é sócia, se rompeu, causando a morte de 19 pessoas, aliado a dano ambiental de grande porte, com repercussão interestadual em decorrência do mar de lama ocasionado no Rio Doce.

Mesmo diante desta tragédia, que evidenciou ao menos riscos de rompimento de outras barragens, não foi identificada atuação estatal no combate a esses riscos. Não houve alteração legislativa para fomentar condicionantes mais rígidas no desenvolvimento da atividade de mineração, em que pese proposta neste sentido. Não houve reestruturação administrativa dos órgãos ambientais, que continuam a desempenhar suas funções com déficit de pessoal. Não houve uma virada jurisprudencial para proibir a atuação de mineradoras que não cumpram todas as condicionantes previstas para o exercício da atividade, sob o entendimento de que tais condicionantes são meramente formais, não geradores de danos.

Em resumo, o fato foi tratado de forma isolada, sob a perspectiva do dano ambiental causado, não havendo a atenção necessária aos riscos e perigos evidenciados a partir dele. Consequentemente, não houve atuação preventiva para evitar fatos semelhantes.

A falta de prevenção pode ser considerada um dos fatores que contribuiu para nova tragédia na mesma atividade desenvolvida, agora no município de Brumadinho, também em Minas Gerais, ocorrido 25 de janeiro de 2019, em empreendimento minerário da sociedade empresarial Vale, vitimando fatalmente mais de 200 pessoas, além de causar novo desastre ambiental de grande proporção.

Ressalte-se que a sociedade empresarial funcionava sem o preenchimento de condicionante básica, que era de isolamento e segurança dos seus trabalhadores quanto ao posicionamento de seu refeitório, o qual se localizava próximo à barragem. $O$ desrespeito a esta condicionante foi motivo crucial para o elevado número de vítimas fatais. Assim, se houvesse seriedade e priorização na proteção coletiva preventiva, estas mortes teriam sido evitadas, haja vista que a falta de cumprimento da condicionante ocasionaria o fechamento do empreendimento até que tal requisito fosse sanado.

Motivações financeiras, próprias de Estado Social e de uma sociedade industrial violadora de direitos fundamentais na tentativa de suprir a fome das pessoas, não servem como paradigma de atuação do Estado brasileiro, que pretende ser democrático, transformando positivamente a sociedade contemporânea. Para tanto, educação com ética, formadora de cidadãos solidaristas e com responsabilidade social; legislação e administração que tratem de forma séria o direito coletivo preventivo e mudança de filosofia do Judiciário como

\footnotetext{
${ }^{10}$ Art. 13. Havendo condenação em dinheiro, a indenização pelo dano causado reverterá a um fundo gerido por um Conselho Federal ou por Conselhos Estaduais de que participarão necessariamente o Ministério Público e representantes da comunidade, sendo seus recursos destinados à reconstituição dos bens lesados.
} 
A CONSCIENTIZAÇÃO QUANTO À NECESSIDADE DE ATUAÇÃO COM SERIEDADE NA PROTEÇÃO COLETIVA PREVENTIVA UM MECANISMO PARA A TRANSFORMAÇÃO DA SOCIEDADE E DO ESTADO BRASILEIRO

Rodrigo Antônio Ribeiro Storino - Eloy Pereira Lemos Júnior

verdadeiro vetor de elaboração de políticas públicas para acesso à Justiça, são medidas que se impõem para o exercício de fato do Estado Democrático Brasileiro idealizado pelo constituinte de 1988.

\section{CONSIDERAÇÕES FINAIS}

Demonstrado ao longo desta pesquisa que a priorização da proteção coletiva preventiva é mecanismo eficaz para inibir danos coletivos, bem como fazer cessar a reiteração de práticas ilícitas geradoras de danos sociais graves e irreversíveis.

A Constituição Federal de 1988 instituiu o Estado Democrático de Direito Brasileiro, ofertando um modelo de constitucionalismo próprio. Este modelo parte de uma nova summa divisio, na qual os direitos fundamentais se dividem em individuais e coletivos.

O modelo de constitucionalismo brasileiro, como forma de efetivar um verdadeiro Estado Democrático, transformador para melhor do cotidiano das pessoas, pressupõe o respeito e eficácia aos direitos fundamentais.

Nesta lógica, os direitos fundamentais da coletividade previstos constitucionalmente, sob a perspectiva neoconstitucionalista, possuem aplicabilidade jurídica direta para interferir no desenvolvimento social e alcance prático do objetivo de construção de uma sociedade brasileira livre, justa e solidária.

O direito coletivo passou a ter orientações gerais próprias, entre as quais se destacam a máxima amplitude e atuação prioritária na proteção coletiva preventiva, de modo a evitar danos sociais típicos da globalizada sociedade de risco contemporânea.

O Direito, em especial o coletivo, passou a atuar não somente a partir da ocorrência dos danos, mas antes disso, buscando preveni-los, combatendo os perigos e riscos detectados.

Para tanto, desenvolveu os princípios de prevenção e precaução, que permitem imposição de obrigações para fazer cessar os perigos e riscos potenciais causadores de danos, atuando para minorar as incertezas que permeiam a sociedade atual.

Além disso, a responsabilidade civil foi multifuncionalizada para alcançar não somente a compensação pelo dano causado, mas em especial para desempenhar funções de prevenir novas condutas semelhantes, e ainda punir, quando necessário, atores que intencionalmente causam perigos e riscos graves.

O Direito brasileiro possui sistematização normativa adequada para prevenir danos sociais. Esta prevenção não se efetiva devido à falta de seriedade com a qual a sociedade e o Estado brasileiro tratam os perigos e os riscos.

Na pesquisa, citando fatos notórios ocorridos recentemente no Brasil, comprovou-se que o Estado e a sociedade brasileira transigem com a violação de direitos fundamentais enquanto estes não causam danos. Ou seja, mesmo conhecedora dos perigos e dos riscos, não há atuação preventiva, optando-se, na maioria das vezes em nome de fatores individualistas e patrimoniais, pela manutenção do risco e do perigo, sob a crença de que não irão se materializar.

A realidade dos danos sociais no Brasil comprova que tal crença, que na verdade se traduz em inércia de atuação preventiva, não pode perdurar, sob pena de não se instituir de fato o projeto de um Estado Democrático de Direito.

Conclui-se pela necessidade de modificação de filosofia e postura da sociedade e Estado brasileiro, para a aplicação com seriedade da sistematização jurídica já existente, como mecanismo de evitar danos sociais graves e irreversíveis.

Não se amolda ao modelo constitucional brasileiro a filosofia individualista e patrimonialista própria de um Estado Liberal, devendo os direitos serem exercidos sem prejudicar os interesses sociais.

Não é compatível com o modelo constitucional brasileiro a postura passiva da nossa sociedade e Estado, devendo agir no combate aos perigos e riscos, prevenindo os danos sociais de acordo com o princípio da priorização da proteção coletiva preventiva.

Pelo exposto, confirmada a hipótese científica da pesquisa de que em virtude do modelo de constitucionalismo brasileiro adotado a partir de 1988, o qual dividiu o ordenamento jurídico pátrio em direitos individuais e coletivos, estipulando como ponto marcante de seu perfil a proteção coletiva preventiva, cabe à 
A CONSCIENTIZAÇÃO QUANTO À NECESSIDADE DE ATUAÇÃO COM SERIEDADE NA PROTEÇÃO COLETIVA PREVENTIVA:

UM MECANISMO PARA A TRANSFORMAÇÃO DA SOCIEDADE E DO ESTADO BRASILEIRO

Rodrigo Antônio Ribeiro Storino - Eloy Pereira Lemos Júnior

sociedade e ao Estado brasileiros atuação precaucional na identificação e combate a ilícitos como mecanismo de prevenção de danos sociais.

\section{REFERÊNCIAS}

ALEXY, Robert. Teoria da Argumentação Jurídica: a teoria do discurso racional como teoria da justificação jurídica. Tradução Zilda Hutehinson Schild Silva. São Paulo: Landy, 2001.

ALMEIDA, Gregório Assagra de. Direito material coletivo: superação da summa divisio direito público e direito privado para a nova summa divisio constitucionalizada. Belo Horizonte: Del Rey, 2008.

BARROSO, Luiz Roberto. Neoconstitucionalismo e constitucionalização do direito: o triunfo tardio do direito constitucional no Brasil. Revista de Direito Constitucional e Internacional. São Paulo: Revista dos Tribunais, 2007, v. 58, p. 132.

BRASIL. Constituição da República Federativa do Brasil. 1988. Disponível em: http://www.planalto.gov.br/ccivil_03/leis/18935. htm. Acesso: 5 maio 2021.

BRASIL. Lei no 7.347, de 24 de julho de 1985. Disciplina a ação civil pública de responsabilidade por danos causados ao meio-ambiente, ao consumidor, a bens e direitos de valor artístico, estético, histórico, turístico e paisagístico e dá outras providências. Disponível em: http://www.planalto.gov.br/ccivil_03/leis/I7347orig.htm. Acesso em: 5 maio 2021.

BRASIL. Lei no 8.078, de 11 de setembro de 1990 - Código de Defesa do Consumidor. Dispõe sobre a proteção do consumidor e dá outras providências. Disponível em: http://www.planalto.gov.br/ccivil_03/leis//8078compilado.htm. Acesso em: 5 maio 2021.

BRASIL. Superior Tribunal de Justiça. REsp 215607/RJ. Relator: Ministro Sálvio de Figueiredo Teixeira. 4a turma. DJ 13 set. 1999. Disponível em: https://stj.jusbrasil.com.br/jurisprudencia/8383020/recurso-especial-resp-215607-rj-1999-0044685-2. Acesso em: 5 maio 2021.

BRASIL. Superior Tribunal de Justiça. REsp295175/RJ. Relator: Ministro Sálvio de Figueiredo Teixeira. 4a turma. DJ 2 abr. 2001. Disponível em: https://stj.jusbrasil.com.br/jurisprudencia/316504/recurso-especial-resp-295175-rj-2000-0138885-1. Acesso em: 5 maio 2021.

CANOTILHO, José Joaquim Gomes. Direito Constitucional e Teoria da Constituição. Coimbra: Almedina, 1998.

DWORKIN, Ronald. Levando os Direitos a Sério. São Paulo: Martins Fontes, 2002.

HÄBERLE, Peter. Hermenêutica constitucional: a sociedade aberta dos intérpretes da constituição; contribuição para interpretação pluralista e procedimental da constituição. Tradução Gilmar Ferreira Mendes. Porto Alegre: Fabris, 1997.

JONAS, Hans. O princípio da responsabilidade. Tradução Marijane Lisboa e Luiz Barros Nuntez. Rio de Janeiro: Contraponto PUC, 2006.

LEMOS JUNIOR, Eloy Pereira; SILVA, Fátima Cristina da. Teoria da Modernidade Líquida: fluidez social e os novos desafios para a interpretação das leis para a solução dos vários novos conflitos no direito de família. Revista Quaestio luris, Rio de Janeiro, v. 9, n. 2, p. 911-941, mar. 2016.

LOPEZ, Teresa Ancona. Responsabilidade Civil na Sociedade do Risco. In: LOPEZ, Teresa Ancona; LEMOS, Patrícia Faga Iglecias; RODRIGUES JUNIOR, Otavio Luiz (org.). Sociedade de risco e direito privado: desafios normativos, consumeristas e ambientais. São Paulo: Atlas, 2013.

ONU. Organização das Nações Unidas. Carta do Rio de Janeiro - Conferência Geral da Nações Unidas sobre o Meio Ambiente. Rio de Janeiro, 1992. Disponível em: http://portal.iphan.gov.br/uploads/ckfinder/arquivos/Carta\%20do\%20Rio\%201992.pdf. Acesso em: 6 maio 2021.

PIOVESAN, Flávia. Direitos humanos e o direito constitucional internacional. 4. ed. São Paulo: Max Limonad, 2000.

PULIDO, Carlos Bernal. El princípio de proporcionalidad y los derechos fundamentales. Madrid: Centro de Estudos Políticos y Constitucionales, 2003.

ROSENVALD, Nelson. As funções da responsabilidade civil: a reparação e a pena civil. 2. ed. São Paulo: Atlas, 2014.

SARLET, Ingo Wolfgang. A eficácia dos direitos fundamentais. 5. ed. Porto Alegre: Livraria do Advogado, 2005.

SILVA, Virgílio Afonso da. A constitucionalização do direito: os direitos fundamentais nas relações entre particulares. São Paulo: Malheiros, 2005.

STRECK, Lenio Luiz. Hermenêutica e Concretização da Constituição: as possibilidades transformadoras do direito. Revista Latino Americana de Estudos Constitucionais. Belo Horizonte, Del Rey, n. 1, 2003.

VAZ, Caroline. Funções da responsabilidade civil: da reparação à punição e dissuasão. Porto Alegre: Livraria do Advogado, 2009. 